Research Article

\title{
Physicochemical and Vibration Analysis of Christmas Tree Four-Way Flange Failure under Fracturing Process
}

\author{
Zhaoming Zhou $\mathbb{D}^{1},{ }^{1}$ Dawen Gong, ${ }^{1}$ Kelong Yang, ${ }^{2}$ Zhong Zeng, ${ }^{3}$ and Zhou Xiao ${ }^{4}$ \\ ${ }^{1}$ School of Mechatronic Engineering, Southwest Petroleum University, Chengdu 610500, China \\ ${ }^{2}$ PetroChina Southwest Oil and Gasfield Company, Chengdu 610500, China \\ ${ }^{3}$ HSE Quality Surveillance \& Inspection Research Institute, CNPC Chuanqing Drilling Engineering Company Limited, \\ Guanghan 613800, China \\ ${ }^{4}$ Drilling and Production Engineering Technology Institute of CNPC Chuanqing Drilling Engineering Co. Ltd., \\ Guanghan 613800, China
}

Correspondence should be addressed to Zhaoming Zhou; zhouzhaom@126.com

Received 14 February 2020; Revised 9 June 2020; Accepted 25 June 2020; Published 17 July 2020

Academic Editor: Reza Kolahchi

Copyright (c) 2020 Zhaoming Zhou et al. This is an open access article distributed under the Creative Commons Attribution License, which permits unrestricted use, distribution, and reproduction in any medium, provided the original work is properly cited.

\begin{abstract}
When a wellhead gas production tree in a certain oilfield block fracturing completed 12 layers and 22 layers and then the bottomup discharge operation was performed, the Wellhead four-way suddenly suffered erosion failure. This is the seventh failure of this operation. In order to obtain the cause of failure, the chemical analysis, hardness testing, tensile property testing, and finite element structural dynamic analysis are used to analyze the failure of the cross connection. The results of physical and chemical analysis show that the chemical composition, hardness, and tensile properties of the failed parts meet the requirements of the standard, not the problem of the material of the work piece. Due to the high-frequency vibration generated by the three-phase fluid in the pipeline during the discharge process, different types of vibration and deformation of the four-way valve and the valve body occur. The dimensions of the on-site structural parts were measured, and the bolt sizes were found to be different. A finite element model was established based on the measured data for dynamic analysis. Through physical and chemical tests and theoretical calculations, it is found that the cause of failure is the unbalanced load and resonance of the bolt, and the nut undercuts under high-frequency vibration, which causes leakage at the flange connection and eventually causes erosion failure. It is recommended to regularly use an electronic torque wrench to test the pretightening force of each bolt to prevent vibration and failure due to inconsistent pretightening force of the bolts.
\end{abstract}

\section{Introduction}

Wellhead gas tree cross is an important wellhead equipment. It consists of main gate, cross flange, tubing gate, needle valve, pressure measuring gate, and casing gate. It is used to open and close the well and adjust the pressure. The main devices for operations such as gas volume, circulating well killing, down-pressure gauge pressure measurement, and wellhead pressure measurement are key safety pressure-bearing components that have failed repeatedly. The site urgently needs to obtain the failure mechanism and propose countermeasures. Krishna et al. [1] established a finite element model for bolted flange joints. The loading and unloading characteristics of the gaskets were obtained through experiments. The analysis showed that the distributed contact stress has a greater impact on the sealing performance than the flange specified by ASME rotation limit. Zhang et al. [2] studied the fracture of the four-way flange of the gas production tree at the KQ 65 wellhead through mechanical property testing and metallographic analysis and concluded that the fracture failure of the KQ65 wellhead production tree was caused by coupling effect of brittle microstructure and local stress concentration. Navas [3] and others used physical and chemical analysis, SEM-EDX analysis, and other analytical methods to study 
the erosion failure occurred in the wellhead choke. Circumferential channel creates a leak. Chen et al. [4] used SEM, EDS, tensile test, and fracture mechanics methods to carry out a case study on the failure of steam pipeline assembly equipment in a chemical plant, revealing and discussing the causes of failure, fracture mechanism, and failure mode. The fatigue life of mounting flange bolts was predicted. Tafreshi and Dover [5] used the finite element method to analyze the stress of drill string threaded connection and studied the full three-dimensional model of the connector under bending and torsional loads. There is a slight change in thread geometry, but it can increase the fatigue life of the thread. Based on the strength and sealing requirements, Wang et al. [6] analyzed the integrity and tightness of the bolt flange connection with the help of Waters formula and finite element calculation and classified and evaluated the flange strength classification and sealing. These can provide reference for practical application. Feng et al. [7] used chemical analysis and metallographic analysis to analyze the failure of the pipeline by a combination of spectroscopic, potential analysis, and X-ray diffraction. It is concluded that, before service, due to the presence of residual water after the hydrostatic test, it is easy to cause pipeline corrosion. After service, with the lower flow rate and prolonged shutdown, water settles to the bottom of the pipeline, which may also cause corrosion, and the presence of inclusions or small holes in the pipe body also accelerates the penetration rate of the pipeline. Wang et al. [8] others analyzed the causes of flange fractures by observing the appearance of cracks and fractures, metallographic analysis, and material composition detection. The author believes that the cracking mode of the flange is the stress corrosion caused by the noncompliance of the material grade and design requirements of the flange. Han et al. [9] established a finite element model of the connection consisting of flanges, gaskets, and bolts and studied the effects of bolt pretightening force and medium pressure on flange stress, strain, and sealing performance. It is concluded that the maximum von Mises stress value of the integral flange structure after pretightening and work occurs at the side of the bolt hole near the axis and at the connection of the flange neck and flange. The greater the pretightening force of the bolt, the greater the von Mises stress, contact stress, and deformation of the flange. $\mathrm{Li}$ [10] established the finite element model of flange, cross and octagonal steel ring based on the actual fracture of the flange, and studied the effects of different loads on the mechanical strength and sealing performance of the three components. The authors believe that as the external load increases, the stress and displacement of the flange and the cross section are continuously increasing. The maximum stress of the flange is greater than that of the cross and octagonal steel ring, which is a direct load. Abedi et al. [11] studied the cracking failure of an oil pipeline by means of microstructure analysis, corrosion product analysis, optical metallographic analysis of corrosion cross sections, fracture analysis, and energy spectrum analysis. The authors believe that carbonate-bicarbonate-induced stress corrosion cracking is the main cause of rupture and leakage of buried pipelines. Long et al. [12] others used a direct-reading spectrometer, Rockwell hardness tester, optical microscope analyzer, scanning electron microscope, energy dispersion spectrometer, electrochemical method, and finite element method to analyze the failure of a tubing pump. The authors believe that higher concentrations of down hole media $\mathrm{CO}_{2}$ and $\mathrm{Cl}^{-}$are the environmental factors of damage, and the alternating stress caused by the cyclic movement of the pump is the main stress factor of the damage, and the high stress concentration of the threaded joint further causes cracking. Zhang et al. [13] analyzed the macroscopic morphology and microstructure of the cracks in the flanges of the holes, combined with metallographic analysis, mechanical properties testing, chemical composition analysis of flange materials, and energy spectrum analysis. The main reason for cracking is liquefaction. Cracking and sensitization of the flange material make the failure even more serious. Hu et al. [14] others performed optical microscopy on the failed copper alloy flange and analyzed the corrosion products by XPS. The reason for the failure is that, due to the limited deformation of the polytetrafluoroethylene, the polytetrafluoroethylene on the Monel gasket cannot enter the hole formed by dezincification and corrosion in the copper alloy, and then water passes through the continuous channel, causing the flange to leak. Zhu et al. [15] used scanning electron microscope and optical microscope to analyze the macro- and microstructure of the broken bolt, studied the properties of the material through chemical composition and metallographic structure, and established a finite element analysis of the connection system to maximize the stress The criterion evaluates the overall stress distribution. The authors believe that the cause of the fracture is high-cycle fatigue, and the initial location of the crack is consistent with the high stress concentration at the location of sudden change in curvature. Yi et al. [16] performed valve failure analysis by means of visual inspection, stereo microscope, optical microscope, scanning electron microscope, and computational fluid dynamics (CFD). The morphological analysis shows that the craters on the valve plug and the cage, especially the craters at the end of the valve plug, are mainly caused by cavitation, and the damage of the groove is corrosive caused by the impact of high-speed water. In a certain oilfield, the gas pressure of the wellhead gas tree was tested to $70 \mathrm{Mpa}$. When the Schlumberger fracturing process was performed, the maximum construction pressure was $65 \mathrm{MPa}$, and when the blowout operation was carried out after the cumulative fracturing was completed in the 22 layers of the $12^{\text {th }}$ stage, the wellhead big tree suddenly leaked. Seven failures of the four-way flange caused by the wellhead blowout operation have occurred so far, but no failure mechanism has been found. This article combines physical and chemical analysis, structural calculation and analysis of flange connection with detection equipment, and numerical simulation analysis methods in conjunction with the failure condition of the flange in the field, in order to find the cause of the failure of the four-way flange.

\section{Physicochemical Analysis}

When the gas production tree of an oil field company was injecting gas from the bottom to top, a puncture occurred at the connection between the wellhead big cross and No. 3 valve. Figure 1 below is a schematic diagram of the wellhead 
installation of the gas production tree. No. 2 valve and No. 3 valve connected to the big cross during the injection are both open. Figure 2(a) is the failure morphology of No. 3 valve body, and Figure 2(b) is the failure morphology of the joint between the cross and No. 3 valve, and the serial numbers 1-8 are marked on the bolt positions. During the fracturing process, the pressure sand, backflow fluid, natural gas, etc. in the pipeline form a three-phase flow. When the three-phase flow is discharged from the four-way through No. 3 valve, the vibration of different frequencies occurs in the valve body. Vibration causes leakage at the joint between the tree and No. 3 valve, eventually resulting in erosion failure. From Figure 2, it can be observed that there are obvious erosion marks on the failed tee and the valve. As shown in Figure 3, bolts and nuts at the flange joint of the four-way flange are found to have inconsistent bolt sizes after field measurement. The bolts have been replaced. The bolts on the fourway bolts are labeled B7 (left); bolts labeled 2, 3, and 4 are labeled HD B7 (center); bolts labeled 5 and 6 are labeled LL B7 (right). Specific specifications are shown in Table 1 below.

\section{Chemical Composition Analysis}

The material selected for the four-way flange is KQ52-35 steel, and KQ52-35 is an alloy steel containing alloy elements $\mathrm{Mn}, \mathrm{Cr}$, and Mo. The chemical composition of the four-way flange and the connecting valve was measured using a mobile direct-reading spectrometer. The specific chemical composition is shown in Table 2. The results show that the chemical composition of the four-way flange and the connecting valve meets the requirements of the standard.

\section{Hardness Test}

The Rockwell hardness tester is used to measure the hardness of the failed valve and the cross. In order to accurately reflect the true hardness of the failed valve and cross, according to the international standard GB/T 230.1-2018, 5 points were selected on the valve and cross to measure. There are 5 test points on the valve: one at the horizontal symmetry of the flange at the nonspilled end of the failed valve, one at the horizontal symmetry of the flange at the pierced end of the failed valve, and the valve body of the failed valve. A total of 5 test points on the four-way body are, respectively, taken at the four-way body, the four-way upper flange symmetry point, and the four-way lower flange symmetry point. The Rockwell hardness test results are shown in Table 3. The test results show that the failed valves and crosses have higher hardness and meet the standard requirements.

\section{Bolt Tensile Performance Test}

The WAW-Y500 universal material testing machine was used to test the connecting bolts. There were 7 bolts participating in the test. Since the failed valve is No. 3 valve, 5 of them are the connecting bolts of the four-way and No. 3 valves. No. 3 bolts labeled B7, No. 1 and No. 2 bolts labeled HD B7, and No. 1 and No. 2 bolts labeled LL B7. The other two bolts are the connecting bolts of the four-way valve and

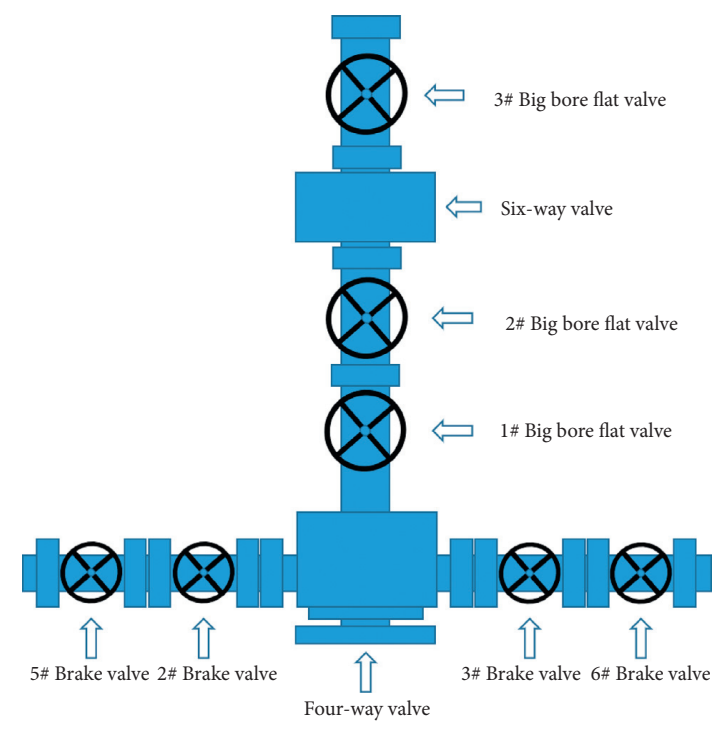

Figure 1: Schematic diagram of wellhead installation of gas production tree.

No. 2 valve, which are marked as B1 No. 1 and No. 2 bolts. Table 4 below shows the results of testing the tensile properties of the bolts. Comparing the measured values with the standard requirements, it can be seen that the connecting bolts participating in the test all meet the tensile performance requirements.

\section{Physical Model Establishment}

After a series of physical and chemical analysis, the results show that the chemical composition, hardness, and tensile properties meet the standard requirements, not the failure caused by the material of the workpiece itself. Because the three-phase fluid in the pipeline will cause high-frequency vibration when the gas extraction tree is performing the discharge operation, a finite element structural dynamic analysis is performed on the four-way connection structure. Due to the symmetrical structure of the gas production tree at the wellhead, during the fracturing process, No. 2 gate valve and No. 1 large-diameter flat valve are closed, and the three-phase flow is discharged from the large cross through No. 3 valve and No. 6 valve. According to the installation method and drawing size, the structure analysis of No. 6 valve, No. 3 valve and the four-way connection is mainly focused on, ignoring other models of the structure, and the solid model established is shown in Figure 4, which is convenient for subsequent finite element calculation. According to the established solid finite element model, the mesh is divided, and the mesh quality meets the requirements. In order to simulate the failure process, a boundary condition was applied to the model. During the discharge process, a static pressure load of $22 \mathrm{MPa}$ was applied to the pressure-bearing part of the inner hole, and a fixed constraint was imposed on the upper and lower parts of the cross. The bolt model is M22, and the preload force is loaded during installation. The preload force is calculated according to the standard recommended formula, $\mathrm{Fv}=(0.5 \sim 0.7) \sigma \mathrm{As}$, where $\mathrm{Fv}$ is the preload force, $s$ is the yield strength of the bolt, and the size is $960 \mathrm{MPa}$, As is the 

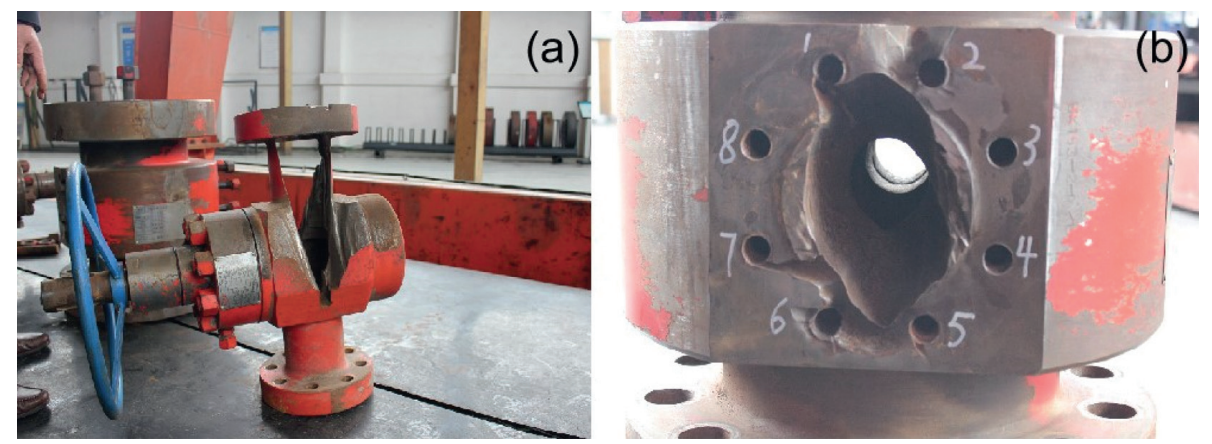

Figure 2: (a) Failure morphology of No. 3 valve body; (b) failure morphology of the joint between the cross and No. 3 valve.

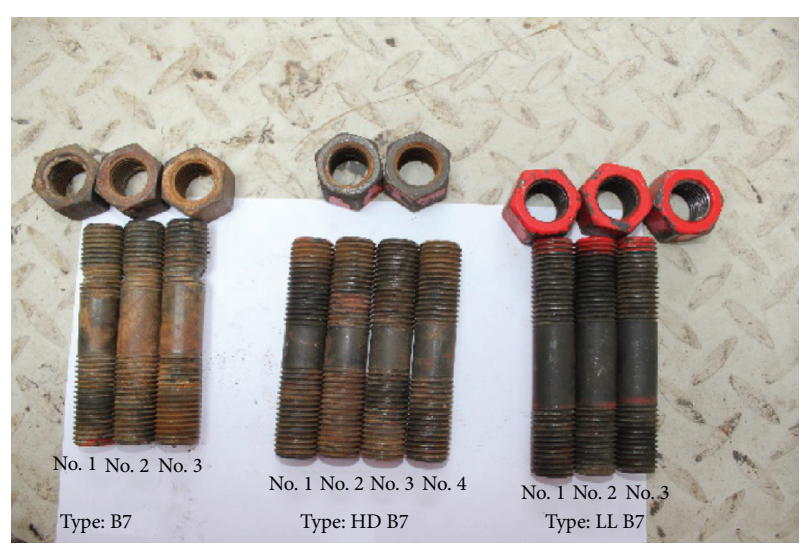

Figure 3: Bolts at flange connections.

nominal stress cross-sectional area of the bolt (the nominal diameter of the thread), and the nominal stress cross-sectional area of the M22 bolt is $303 \mathrm{~mm}^{2}$. The pretightening force of the bolt is calculated to be about $150000-200000 \mathrm{~N}$. Three different types of bolts were used on the site. Due to the different pretension forces applied to bolts of different lengths, the stress and deformation of the bolts and structures were analyzed under multiple loads.

\section{Structural Vibration Analysis}

Analyze the structural analysis of the flange connection during the discharge process and carry out the force analysis of the four-way flange connection subjected to vibration load, including modal analysis and harmonious response analysis.

\section{Modal Analysis}

Perform modal analysis of the structure, analyze the characteristics of the main modes of each order in the frequency range, where the flange connection structure is affected by the modal analysis method, and predict the structure generated by external or internal vibration sources in this frequency band. For finite element analysis, in general, the calculation of the natural frequencies of the first 6 orders can basically meet the general requirements. The calculation of the natural frequencies of the first 10 orders in this paper can meet the engineering calculation accuracy. Observing the mode shapes of ten orders, it can be found that the natural frequency gradually increases, and the number of deformation increases and decreases. From the analysis of the overall mode shape, the trend of the mode shapes of each order is obtained. The two valves are mostly deformed up and down in the horizontal direction, and the amount of deformation varies between $2.47 \mathrm{~mm}$ and $5.89 \mathrm{~mm}$. This amount of deformation will accelerate the failure of the bolt connection stability, especially from the fourth, eighth, and tenth mode shapes found that the vibration characteristics are at the flange connection, which easily leads to deformation of the flange connection. The frequency and formation of each order are shown in Table 5 below. It can be found from the frequency values of each order in Table 5 that the modal frequency of the structure vibration is in the range of $40-1200 \mathrm{~Hz}$. From the continuous equation, momentum equation, and the wave equation, we can get the relationship between the inlet and outlet pressure and speed of the straight pipe:

$$
\left[\begin{array}{l}
p_{2} \\
u_{2}
\end{array}\right]=\left[\begin{array}{cc}
\cos \frac{\omega}{a} l & -\rho_{0} a \sin \frac{\omega}{a} l \\
\frac{1}{\rho_{0} a} \sin \frac{\omega}{a} l & \cos \frac{\omega}{a} l
\end{array}\right]\left[\begin{array}{l}
p_{1} \\
u_{1}
\end{array}\right],
$$

where $\rho_{0}$ is the average density, unit: $\mathrm{kg} \mathrm{m}^{-3} ; a$ is the sound velocity of the medium, unit: $\mathrm{m} \mathrm{s}^{-1} ; a$ is the circular frequency of the pulsation, unit: $\operatorname{rads}^{-1}$; unit: $\mathrm{m}$. Set the boundary condition to one end as the closed end and the other end as the open end. Set the boundary condition between the gas tree and the open end to set the pressure to 0 , and set the pressure to 0 if the pressure is not zero. 0 ; the right end is $p_{2}=0$ and $u_{2}=1$. Substituting these conditions into the above formula, we obtain

$$
\cos \frac{\omega}{a} l=0 .
$$

The iterative method is used to find the natural frequencies of the three-phase currents in the order of 1 to $n$ for each value of $\omega$, from small to large. The calculated frequency of fluid vibration is in the range of $0-1200 \mathrm{~Hz}$. When the vibration frequency of the structure and the fluid are the same, the two will cause resonance increased vibration. 
TABLE 1: Dimensions of four-way flange connection bolts.

\begin{tabular}{lccccc}
\hline Type & Bolt length $(\mathrm{mm})$ & Length of thread $(\mathrm{mm})$ & The polished rod diameter $(\mathrm{mm})$ & Diameter of thread $(\mathrm{mm})$ & Nut height $(\mathrm{mm})$ \\
\hline B7 & 115.19 & 41.57 & 20.26 & 21.82 & 23.62 \\
HD B7 & 105.60 & 43.32 & 20.32 & 21.90 & 24.00 \\
LL B7 & 109.45 & 43.82 & 20.30 & 21.76 & 24.00 \\
\hline
\end{tabular}

TABLE 2: Chemical composition of the four-way flange and connecting valve.

\begin{tabular}{|c|c|c|c|c|c|c|c|c|c|}
\hline Element & $\mathrm{C}$ & $\mathrm{Si}$ & $\mathrm{Mn}$ & $\mathrm{Cr}$ & Mo & $P$ & S & $\mathrm{Ni}$ & V \\
\hline Four & 0.29 & 027 & 0.56 & 101 & 0.18 & 0.015 & 0.008 & 0.03 & $<0.01$ \\
\hline Failu & 0.31 & 0.25 & 0.56 & 0.92 & 0.16 & 0.007 & 0.003 & 0.20 & 0.01 \\
\hline Standard requirement & $0.26-0.33$ & $0.17-0.37$ & $0.40-0.70$ & $0.80-1.10$ & $0.15-0.25$ & $\leq 0.025$ & $\leq 0.025$ & $\leq 0.30$ & $\leq 0.30$ \\
\hline
\end{tabular}

TABLE 3: Rockwell hardness test results.

\begin{tabular}{|c|c|c|c|c|c|}
\hline Measuring position & 1 & 2 & 3 & 4 & 5 \\
\hline \multirow{2}{*}{ Four-way flange measurement results } & 220 & 224 & 232 & 220 & 216 \\
\hline & HBHLD & HBHLD & HBHLD & HBHLD & HBHLD \\
\hline \multirow{2}{*}{ Failure valve measurement results } & 209 & 231 & 234 & 236 & 235 \\
\hline & HBHLD & HBHLD & HBHLD & HBHLD & HBHLD \\
\hline Standard requirement & & & 197 237 HBW & & \\
\hline
\end{tabular}

TABLE 4: Testing results of bolt tensile properties.

\begin{tabular}{|c|c|c|c|c|c|}
\hline & & $\begin{array}{l}\text { Yield strength (YS0.2) } \\
(\mathrm{MPa})\end{array}$ & $\begin{array}{l}\text { Tensile strength } \\
(\mathrm{MPa})\end{array}$ & $\begin{array}{c}\text { Percentage reduction of area } \\
(\%)\end{array}$ & $\begin{array}{l}\text { Elongation } \\
\quad(\%)\end{array}$ \\
\hline \multirow{3}{*}{$\begin{array}{l}\text { Bolt type HD } \\
\text { L7 }\end{array}$} & Measurement no. 1 & 937 & 1044 & 63 & 21.5 \\
\hline & Measurement no. 2 & 954 & 1050 & 64 & 21.0 \\
\hline & $\begin{array}{c}\text { Standard } \\
\text { requirement }\end{array}$ & $\geq 725$ & $\geq 860$ & $\geq 50$ & $\geq 16$ \\
\hline \multirow{3}{*}{ Bolt type LL B7 } & Measurement no. 1 & 1059 & 1119 & 61 & 19.5 \\
\hline & Measurement no. 2 & 1021 & 1093 & 61 & 18.5 \\
\hline & $\begin{array}{c}\text { Standard } \\
\text { requirement }\end{array}$ & $\geq 720$ & $\geq 860$ & $\geq 50$ & $\geq 16$ \\
\hline \multirow{4}{*}{ Bolt type B7 } & Measurement no. 1 & 907 & 995 & 63 & 22.5 \\
\hline & Measurement no. 2 & 876 & 969 & 62 & 20.5 \\
\hline & Measurement no. 3 & 908 & 994 & 63 & 20.5 \\
\hline & $\begin{array}{l}\text { Standard } \\
\text { requirement }\end{array}$ & $\geq 720$ & $\geq 860$ & $\geq 50$ & $\geq 16$ \\
\hline
\end{tabular}

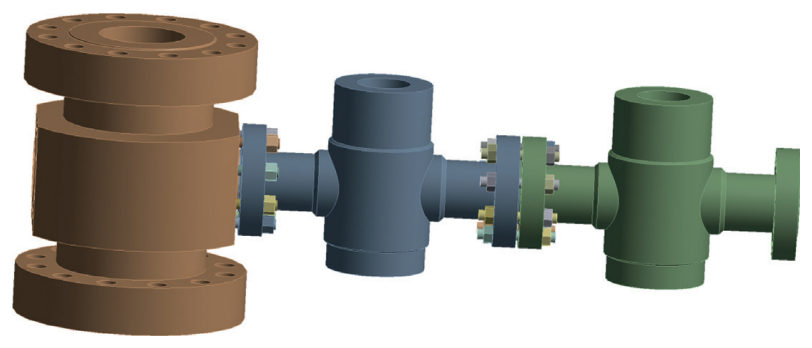

Figure 4: The finite element model established.

\section{Harmonic Response Analysis}

Harmonic response analysis is a technique for analyzing the steady-state response of a structure under a load that changes in a regular manner. Harmonic loads are applied and solved. All applied loads change simply and harmonically at a specified frequency (or frequency range). The deformation is restricted to zero, and the force of the valve body is $10 \mathrm{kN}$ in the vertically upward direction (calculated based on the contact area of the fluid pressure with the hole in the valve body). Figure 5 is the stress cloud diagram of the bolt at different frequencies. When the frequency of the three-phase flow is $40 \mathrm{~Hz}, 240 \mathrm{~Hz}, 552 \mathrm{~Hz}, 688 \mathrm{~Hz}$, and $1104 \mathrm{~Hz}$, the threephase flow in the bolt and the valve body will resonate. As can be seen from the figure, the three-phase fluid and structure did not resonate at a frequency of $1200 \mathrm{~Hz}$, and the stress of the bolt was $20.948 \mathrm{MPa}$. When the resonance occurred, the stress of the bolt was gradually increased. When the frequency was $1104 \mathrm{~Hz}$, the bolt was subjected to the maximum stress. It reaches 2302.2 $\mathrm{MPa}$, far exceeding its yield limit. Figure 6 shows the stress spectrum response curves of No. 1-8 bolts. These parts will produce different magnitudes of stress in the frequency range of $0-1200 \mathrm{~Hz}$. No. 1 bolt is the most stressed, followed by No. 5 and No.6 bolts. As shown in Figure 7, the spectral response curves of the deformation amount of No. 


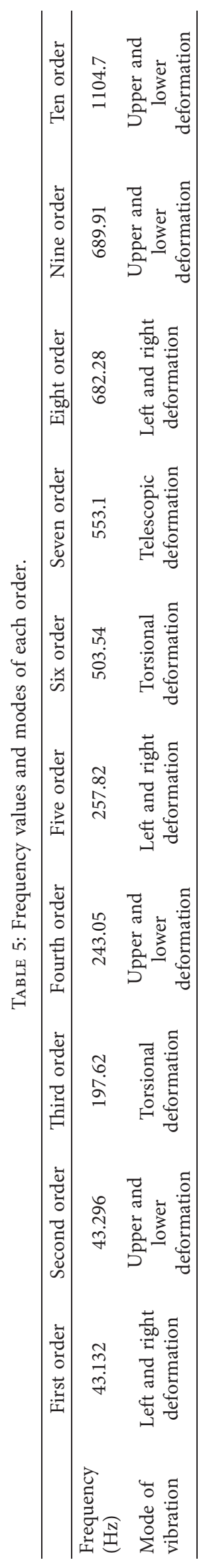




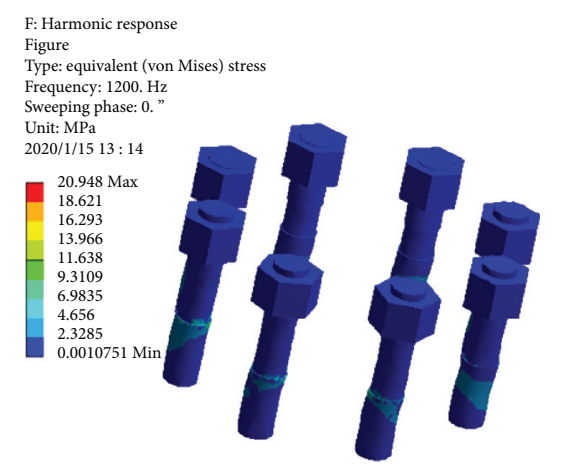

(a)

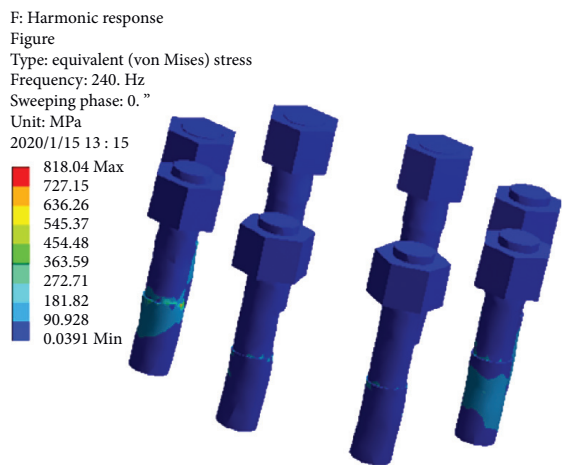

(d)

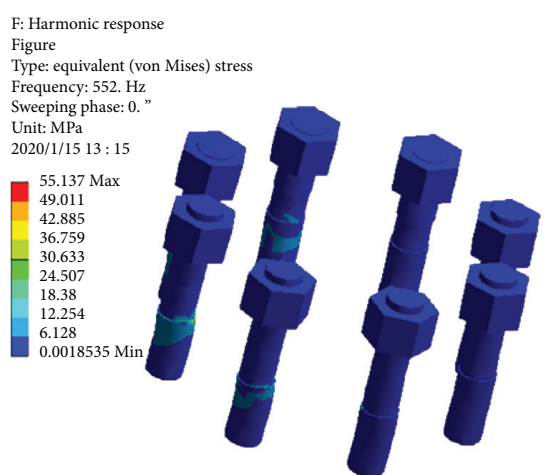

(b)

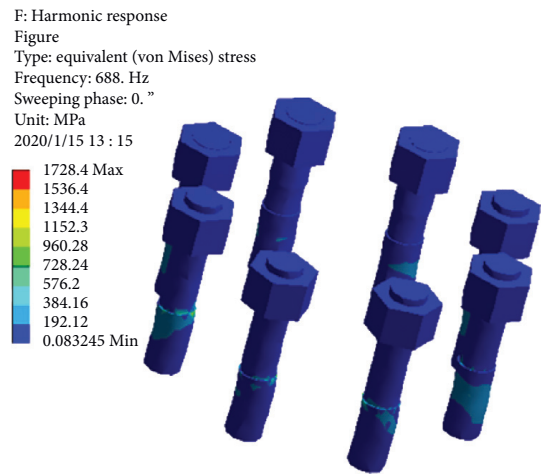

(e)

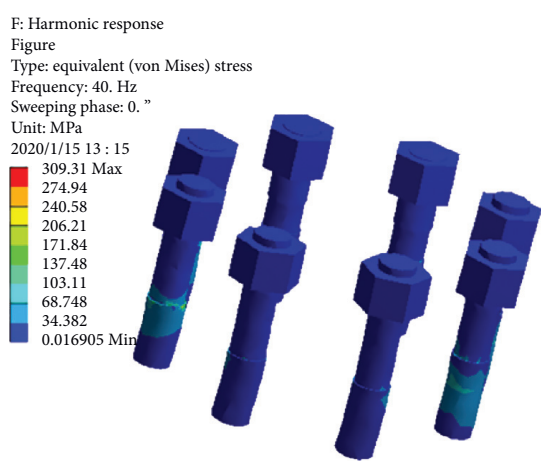

(c)

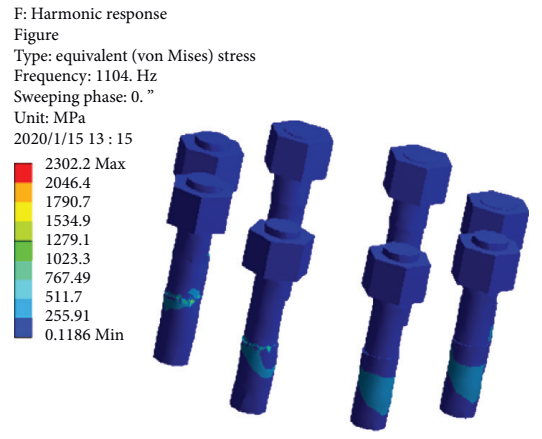

(f)

Figure 5: Stress cloud diagrams of bolts at different frequencies: (a) $1200 \mathrm{~Hz}$; (b) $552 \mathrm{~Hz}$; (c) $40 \mathrm{~Hz}$; (d) $240 \mathrm{~Hz}$; (e) $688 \mathrm{~Hz}$; (f) $1104 \mathrm{~Hz}$.

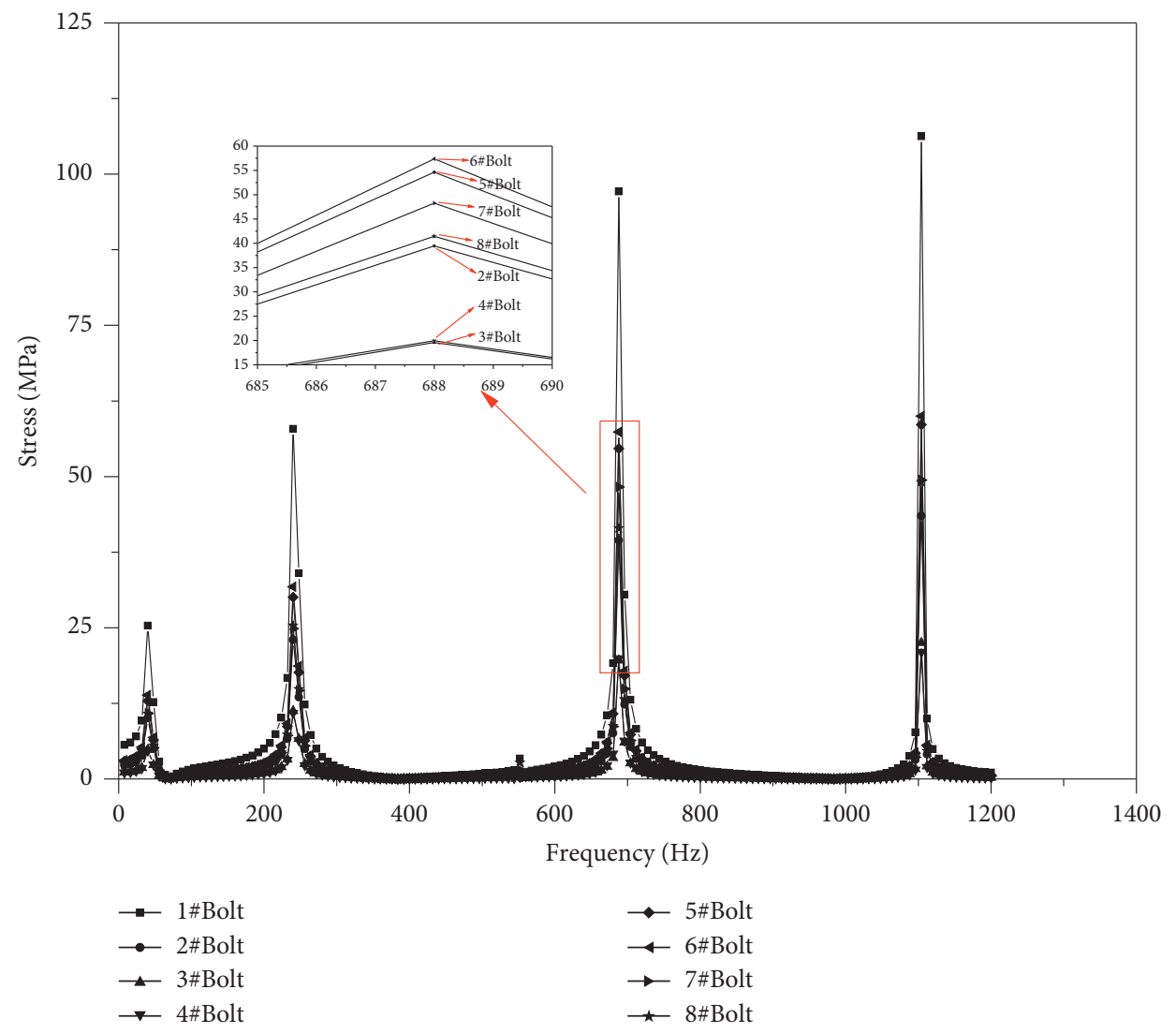

Figure 6: Bolt stress spectrum response curve. 


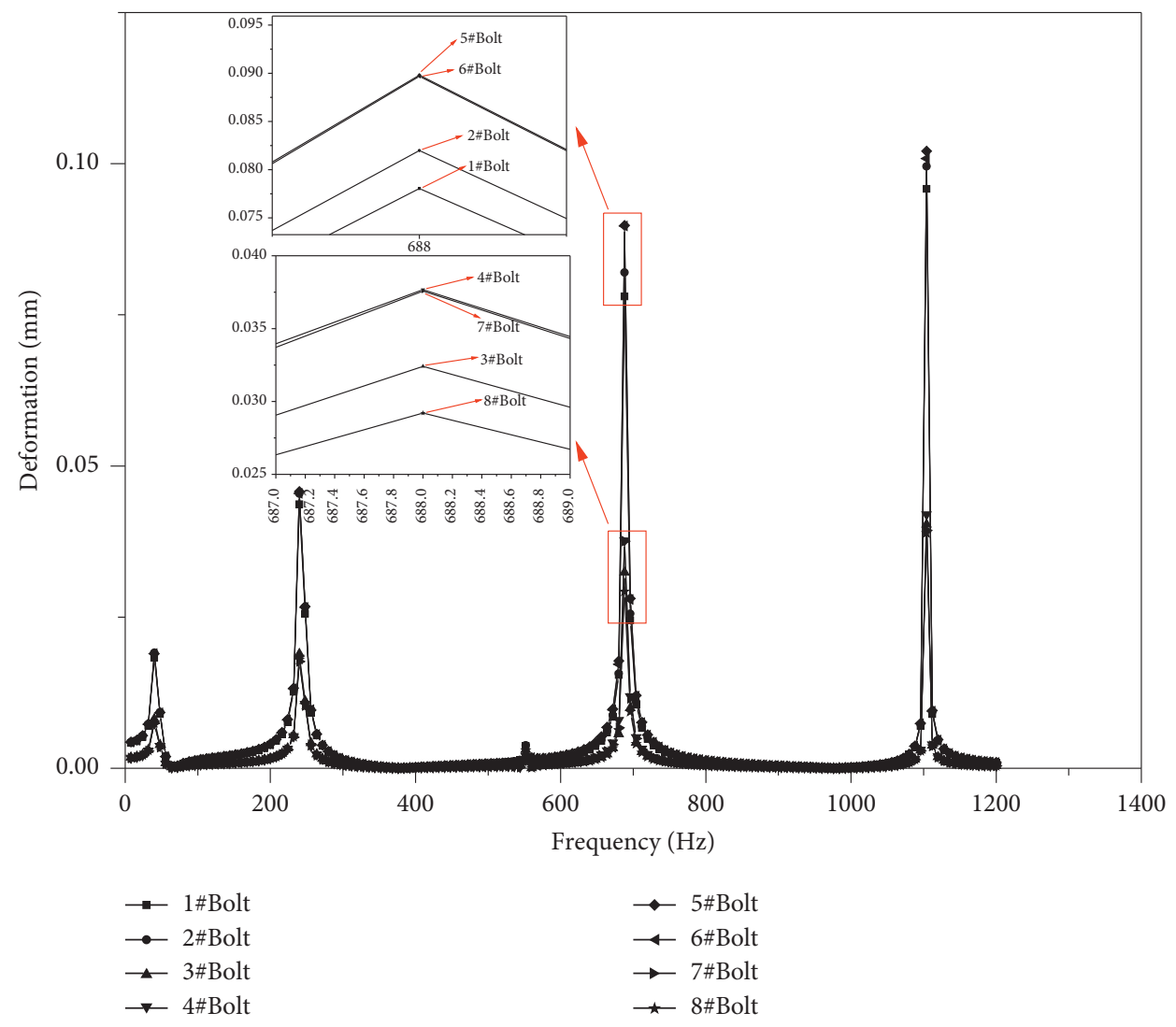

Figure 7: Spectrum response curve of bolt deformation.

1-8 bolts are, respectively, found from the spectral response curves of the deformation amount of bolts. The upper and lower ends of the cross, that is, No. 1, No. 2, No. 5, and No. 6 bolts have a deformation amount greater than $0.08 \mathrm{~mm}$; the left and right ends of the cross, No. 4, No. 7, No. 3, and No. 8 bolts have a small deformation and deformation The volume is about $0.03 \mathrm{~mm}$. The amount of bolt deformation is connected to the cross, and the failure situation at the place coincides. At the same time, there are five peaks in the entire spectral response curve of the deformation. When the frequency of the three-phase flow in the valve is $40 \mathrm{~Hz}, 240 \mathrm{~Hz}$, $552 \mathrm{~Hz}, 688 \mathrm{~Hz}$, and $1104 \mathrm{~Hz}$, the three-phase flow and fourway valve will resonate and cause the vibration to increase. The four-way valve structure is stimulated by the regular vibration, and No. 1, No. 2, No. 5, and No. 6 nuts are most excited by vibration and have the largest amount of deformation. At the same time, the three-phase flow in the valve and the valve body will cause resonance to cause vibration. Because this part is easy to relax, the nut will be reversed due to vibration, eventually the bolt will loosen and fall off, and the wellhead cross and No. 3 valve will have erosion failure.

\section{Conclusion}

After physical and chemical analysis, modal analysis, and harmonious response analysis of the failed four-way flange on the gas production tree, the following conclusions were reached:
(1) Chemical composition analysis, hardness testing, and bolt tensile performance test results show that the chemical composition of the four-way flange and connecting valve meets the requirements of the standard; the failure of the valve and the four-way hardness is higher and meets the standard requirements. The bolts meet the requirements for tensile properties.

(2) From the modal analysis and mode change, it is found that the valve body connection is equivalent to a cantilever beam. The end of No. 6 valve body is not fastened, which will cause No. 6 valve body to have a larger vibration amplitude, affecting No. 3 valve body and tighten the connection. Because the fluid in the blowout prevention pipeline is in a three-phase state, the vibration frequency is increased due to gas-liquid-solid. In addition, different bolt sizes will cause uneven distribution of different vibration deformations of the bolt, which may easily cause loosening accidents.

(3) According to the harmonic response curves of Figures 6 and 7 above, it is found that the bolt will be subjected to different magnitudes of stress in the frequency range of $0-1200 \mathrm{~Hz}$ to produce different degrees of vibration. The maximum stress on the bolt is close to $110 \mathrm{MPa}$, and the vibration of the bolt. The maximum deformation reaches $0.1 \mathrm{~mm}$. 
(4) When the gas extraction tree is performing the spraying operation, the three-phase fluid will generate high-frequency vibration in the pipeline, which will cause the valve body to vibrate up and down. Due to the size of the bolt at the junction of the wellhead cross and No. 3 valve, the length is different, the load on the bolt is in an unbalanced state, and the nut is buckled, which causes leakage at the flange connection. Eventually, the wellhead cross and No. 3 valve have erosion failure.

(5) It is recommended to regularly use an electronic torque wrench to detect the pretightening force of each bolt to prevent vibration and failure due to inconsistent pretightening force of the bolts.

\section{Data Availability}

The data used to support the findings of this study are included within the article.

\section{Conflicts of Interest}

The authors declare that there are no conflicts of interest regarding the publication of this paper.

\section{Acknowledgments}

This work was supported by the Sichuan Science and Technology Program (no. 2020YFG0180), Scientific Research Starting Project of SWPU (no. 2018QHZ014), and National Natural Science Foundation of China (no. 51974271).

\section{References}

[1] M. M. Krishna, M. S. Shunmugam, and N. S. Prasad, "A study on the sealing performance of bolted flange joints with gaskets using finite element analysis," International Journal of Pressure Vessels and Piping, vol. 84, no. 6, pp. 349-357, 2007.

[2] J.-M. Zhang, X. Wang, Y. Zhu, and P. Du, "Failure analysis of a four-way flange cracking in a KQ65 wellhead christmas tree," Journal of Failure Analysis and Prevention, vol. 19, no. 2, pp. 394-401, 2019.

[3] G. Navas and I. C. Grigorescu, Erosion-Corrosion Failures in Wellhead Chokes, NACE International, Houston, TX, USA, 2011.

[4] H.-S. Chen, P.-T. Tseng, and S.-F. Hwang, "Failure analysis of bolts on an end flange of a steam pipe," Engineering Failure Analysis, vol. 13, no. 4, pp. 656-668, 2006.

[5] A. Tafreshi and W. Dover, "Stress analysis of drillstring threaded connections using the finite element method," International Journal of Fatigue, vol. 15, no. 5, pp. 429-438, 1993.

[6] H. Wang, J. Lu, K. Guan et al., "Finite element analysis of strength and sealing of flanges with joints strength and seal FE analysis of combined flanges with a pipe," Pressure Vessel, vol. 2, pp. 22-29, 2012.

[7] Q. Feng, B. Yan, P. Chen et al., "Failure analysis and simulation model of pinhole corrosion of the refined oil pipeline," Engineering Failure Analysis, vol. 106, Article ID 104177, 2019.
[8] Y. Wang, G. Xie, H. Lu et al., "Causes of flange cracking," Failure Analysis and Prevention, vol. 11, no. 6, pp. 369-371, 2016.

[9] C. Han, J. Zhang, and S. Niu, "Strength analysis of flange joints based on finite element method," Petroleum Machinery, vol. 41, no. 4, pp. 98-101, 2013.

[10] C. Li, "Strength analysis and research of wellhead flange connection," Mechanical Research and Application, vol. 31, no. 3, pp. 39-41, 2018.

[11] S. S. Abedi, A. Abdolmaleki, and N. Adibi, "Failure analysis of SCC and SRB induced cracking of a transmission oil products pipeline," Engineering Failure Analysis, vol. 14, no. 1, pp. 250-261, 2007.

[12] Y. Long, G. Wu, A. Q. Fu et al., "Failure analysis of the $13 \mathrm{Cr}$ valve cage of tubing pump used in an oilfield," Engineering Failure Analysis, vol. 93, pp. 330-339, 2018.

[13] Y. Zhang, X. Shang, M. Song, Z. Sun, and S. Xu, "Failure analysis of handhole flange cracking," Engineering Failure Analysis, vol. 96, pp. 100-108, 2019.

[14] Q. Hu, Y. Liu, T. Zhang, and F. Wang, "Corrosion failure analysis on the copper alloy flange by experimental and numerical simulation," Engineering Failure Analysis, vol. 109, Article ID 104276, 2020.

[15] X. Zhu, J. Xu, Y. Liu, B. Cen, X. Lu, and Z. Zeng, "Failure analysis of a failed connecting rod cap and connecting bolts of a reciprocating compressor," Engineering Failure Analysis, vol. 74, pp. 218-227, 2017.

[16] J. Yi, H. Hu, Y. Zheng, and Y. Zhang, "Experimental and computational failure analysis of a high pressure regulating valve in a chemical plant," Engineering Failure Analysis, vol. 70, pp. 188-199, 2016. 